\title{
Formulation Optimization and In-vitro Evaluation of Oral Floating Captopril Matrix Tablets using Factorial Design
}

\author{
Muhammad Ahsan ${ }^{1}$, Nasir Abbas ${ }^{1 \star}$, Amjad Hussain ${ }^{1}$, Hamid Saeed ${ }^{1}$, Pervaiz \\ Akhtar Shah ${ }^{1}$, Sohail Mohammad ${ }^{2}$ and Muhammad Sohail Arshad ${ }^{3}$ \\ ${ }^{1}$ Department of Pharmaceutics, University College of Pharmacy, University of the Punjab, Lahore 54000, ${ }^{2}$ Faculty of Pharmacy, \\ Shifa Tameer-e-Millat University, Islamabad, ${ }^{3}$ Department of Pharmaceutics, Bahauddin Zakriya University, Multan, Pakistan
}

*For correspondence: Email: nasirabbas77@gmail.com; Tel: 0092-331-7724909

\begin{abstract}
Purpose: To develop a zero-order sustained release floating formulation of captopril, and optimize its drug release for enhanced oral bioavailability.

Methods: A relatively new approach, $3^{2}$ full factorial design, was used to formulate floating captopril matrix tablets and to systematically optimize its drug release using varying levels of xanthan gum and hydroxypropyl methylcellulose (HPMC) K100M polymers. Calcium carbonate was used as gasgenerating agent. After setting the levels by preliminary trials, nine tablet formulations (F1 - F9) were

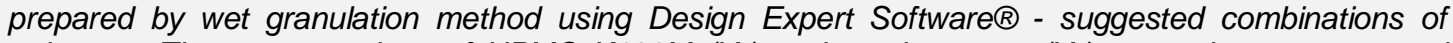
polymers. The concentrations of HPMC K100M $\left(X_{1}\right)$ and xanthan gum $\left(X_{2}\right)$ were chosen as control variables. Conversely, the response variables selected were timed to release $50 \%$ of the drug ( $\left.t_{50 \%}\right)$ at $6 h\left(Q_{6}\right)$ and $12 h\left(Q_{12}\right)$. Fourier transform infrared (FTIR) spectroscopy and differential scanning calorimetry (DSC) were used to assess compatibility between the drug and the excipients. The validity of the developed mathematical equations was assessed by designing three extra check-points.

Results: The response surface plots drawn demonstrated the suitability of the hydrophilic matrixforming agents for formulating controlled release floating tablets of captopril. FTIR and DSC spectra showed no noticeable incompatibility between drug and polymers in both physical mixtures and in formulations. Floating time lag remained $<5.5 \mathrm{~min}$ with floating duration $>12 \mathrm{~h}$. Considerable agreement was observed between predicted and actual release parameters. Fitting the data into different kinetic models showed that non-Fickian behavior for diffusion exponent (n) differed from 0.588 and 0.811 .

Conclusion: Optimum formulation (F4) showed satisfactory release profile. Moreover, the study successfully demonstrated influence of polymer blends in controlling release variables.
\end{abstract}

Keywords: Captopril, Xanthan gum, Hydroxy propyl methyl cellulose , Factorial design, Bioavailability

Tropical Journal of Pharmaceutical Research is indexed by Science Citation Index (SciSearch), Scopus, International Pharmaceutical Abstract, Chemical Abstracts, Embase, Index Copernicus, EBSCO, African Index Medicus, JournalSeek, Journal Citation Reports/Science Edition, Directory of Open Access Journals (DOAJ), African Journal Online, Bioline International, Open-J-Gate and Pharmacy Abstracts

\section{INTRODUCTION}

Gastric residence time (GRT) is the main consideration in the formulation design of stomach specific dosage forms. Rapid gastric emptying leads to reduced efficacy of oral delivery system due to partial release of the drug from the dosage form [1-3]. Various approaches like floating systems [4,5], bioadhesive systems [6], swelling and expanding systems [7], and gastric emptying delayed devices [8] have been reported in literature for gastric retention of drug formulations. These gastro-retentive systems work by retaining the delivery system in the stomach and improve oral bioavailability of drugs that have absorption windows at the upper 
gastrointestinal region $[9,10]$. Among all the techniques, floating drug delivery system (FDDS) is gaining more attention due to the simplicity of the development process.

The FDDS can be developed using two distinct technologies which are effervescent and noneffervescent systems, based on mechanism of buoyancy. Effervescent systems are mostly comprised of swellable polymers and gas forming components like calcium carbonate and/or citric acid [11]. Ultimately, air trapped within these polymers cause the formulation to remain buoyant on the surface of gastric fluid. In contrast, non-effervescent FDDS are commonly fabricated by incorporating suitable gel forming hydrocolloids [12].

Many studies have been conducted in which drugs of different pharmacological groups were fabricated into floating systems $[4,5,13]$. In this study, Captopril was selected as a model candidate for FDDS due to a multitude of reasons.

Captopril is widely used in the treatment of essential hypertension. Its antihypertensive action is due to inhibition of angiotensinconverting enzyme (ACE). The length of therapeutic action after a single dose of Captopril is 6 hours, so to obtain desired therapeutic drug plasma level requires frequent administration $[14,15]$ leading to poor patient compliance. The drug is relatively stable at acidic $\mathrm{pH}$ (1.2) of stomach, and as it moves towards regions of higher $\mathrm{pH}$ along the GIT, the drug shows instability due to degradation reactions $[16,17]$. Moreover, Captopril lies in the Class III of BCS classification showing high aqueous solubility as well as less intestinal permeability leading to variable absorption of drug via the intestine [18]. Owing to free water solubility, the drug can undergo dose dumping and burst phenomenon which can affect its sustained release formulation [19].

The current study effectively utilized polymer composite of xanthan gum and HPMC K100M to formulate floating tablets by optimizing it with 32 full factorial designs. For this purpose, a favorable acceptance criterion was established. Moreover, floating tablets were studied for physical evaluation, FTIR spectroscopy, DSC, invitro floating and dissolution studies.

Previous studies revealed important economical and pharmaceutical advantages of xanthan gum over other polymers [20]. The natural gum possess properties of reduced burst initial release as well as more reproducible and predictable drug release possibly following zero order kinetics [21]. In fact, in addition to reducing overall cost of manufacturing of floating tablet, it has been demonstrated that it imparts biocompatibility and inertness to final formulation [22]. These additional features make this biopolymer a safer and suitable alternative for formulating floating tablets for commercial use.

\section{EXPERIMENTAL}

\section{Materials}

Captopril was a generous gift sample from Glaxosmithkline Pakistan Limited. Xanthan gum was received from Hamdard Laboratories (Herbal Division, Lahore). Lactose was procured from Union Commercial Corporation, Lahore. PVP K30, HPMC K100M and magnesium stearate were sourced from Wilshire Pharmaceuticals (Pvt) Ltd Lahore.

\section{Methods}

\section{Preparation of floating Captopril tablets}

First, weighing of all the ingredients was executed accurately on electronic balance (Shimadzu, Japan). Then for formulation of tablets, Captopril, xanthan gum, HPMC K100M, $\mathrm{CaCO}_{3}$ and lactose in various proportions were sifted through mesh \# 40 and were collected in cone shaped blender and well mixed to get a uniform mixture. The process of granulation was done by preparing slurry of PVP K30 in isopropyl alcohol. Subsequently, drying of granulated material was undergone in a drying oven at 45 ${ }^{\circ} \mathrm{C}$ and dried granules were further passed through sieve \# 16. After mixing with magnesium stearate (1 \%) as a lubricant, granules' compression was undertaken using single stroke machine (Sammi Engineering, Lahore). Final tablet weights could not remain the same which usually require incorporations of varying concentrations of diluents. It was done to avoid any influence on the release profile resulting from change in diluent concentration $(10,13)$. The preparation of nine formulations ( $\mathrm{F} 1$ to $\mathrm{F} 9$ ) was carried out according to the composition shown in Table 1.

\section{Experimental design}

Some possible experimental trials, generated by application of $3^{2}$ factorial design, were conducted to evaluate each independent factor at 3 levels. Formulation combinations (F1 - F9) using factorial design were shown in Table 2. The percentages of HPMC K100M $\left(X_{1}\right)$ and xanthan gum $\left(X_{2}\right)$ were chosen as control variables while 
$t_{50 \%}$ (time to release $50 \%$ of drug), $Q_{6}$ and $Q_{12}$ (quantity of drug released after 6 and $12 \mathrm{~h}$, respectively) were selected as response variables.

Table 1: Composition of captopril floating tablets

\begin{tabular}{lc}
\hline Factor & Amount (mg) \\
\hline Captopril & 50 \\
Xanthan gum & $40-120$ \\
HPMC K100M & $40-120$ \\
CaCO3 & 30 \\
PVPK30 & 10 \\
Magnesium stearate (1\%) & 4 \\
Lactose & 200 \\
\hline
\end{tabular}

Table 2: Factor combinations according to $3^{2}$ design

\begin{tabular}{|c|c|c|c|}
\hline \multirow[t]{2}{*}{ Trail no. } & \multicolumn{3}{|c|}{ Coded factor level } \\
\hline & $\mathrm{X} 1$ & & $\mathrm{X} 2$ \\
\hline 1 & -1 & & -1 \\
\hline 2 & 0 & & -1 \\
\hline 3 & 1 & & -1 \\
\hline 4 & -1 & & 0 \\
\hline 5 & 0 & & 0 \\
\hline 6 & 1 & & 0 \\
\hline 7 & -1 & & 1 \\
\hline 8 & 0 & & 1 \\
\hline 9 & 1 & & 1 \\
\hline \multicolumn{4}{|c|}{ Transformation of coded levels into tangible values } \\
\hline Coded level & -1 & 0 & 1 \\
\hline X1 (HPMC K100M) & 40 & 80 & 120 \\
\hline X2 (xanthan gum) & 40 & 80 & 120 \\
\hline
\end{tabular}

The obtained data underwent response surface computations by fitting into the Design Expert software (Stat-Ease Inc., MN, USA). Response surface graphs were drawn to delineate the effect of HPMC K100M and xanthan gum levels on response variables.

\section{Evaluation of tablet hardness, thickness and diameter}

Physical properties like thickness (mm), crushing strength $\left(\mathrm{kg} / \mathrm{cm}^{2}\right)$ and diameter $(\mathrm{mm})$ for formulated batches of floating tablets were determined using digital hardness tester (Pharma Test, Germany) which can test all these parameters simultaneously.

\section{Fourier transformed infrared (FTIR) spectroscopy}

FTIR spectroscopy was conducted using IR Prestige system (IR Prestige 21, Shimadzu, Japan) to perform compatibility studies by $\mathrm{KBr}$ disc method as described by Sunil et al. The spectral range of $4000-500 \mathrm{~cm}^{-1}$ was used to record spectra of each sample [23].

\section{Differential scanning calorimetry (DSC)}

Thermal studies were conducted using thermal analyzer instrument (SDT Q600, USA) combined with TA software and flow controller to analyze pure drug, polymers and formulated tablets. Aluminium pans (TA, instrument) were used to enclose prepared samples and heating at the rate of $10{ }^{\circ} \mathrm{C} / \mathrm{min}$ was done under nitrogen atmosphere to the specified temperature of 400 ${ }^{\circ} \mathrm{C}[10]$.

\section{In-vitro buoyancy studies}

The simple approach adopted by Booma et al was used to study in-vitro floating properties of matrix tablets. The tablet matrix of each formulations was placed in a $100 \mathrm{ml}$ beaker containing $0.1 \mathrm{~N} \mathrm{HCl}$. The time availed by tablets to appear on the surface of the medium for floating was noted as the buoyancy lag time while the time during which tablets continuously remained buoyant on the surface was called floating duration. These parameters were examined by visual inspection [12].

\section{Drug content determination and in-vitro release studies}

Dissolution USP apparatus II (Paddle method) was used to examine the release of drug from all formulations. Dissolution medium $(0.1 \mathrm{~N} \mathrm{HCl}$, no enzyme) of $900 \mathrm{ml}$ was used to perform dissolution testing at $37 \pm 0.5^{\circ} \mathrm{C}$ and ran at 50 rpm. Sample solution of $5 \mathrm{ml}$ was taken out from the dissolution medium and an immediate replacement of fresh medium was undertaken to maintain sink conditions. A sinker (platinum wire) was used to confine the tablet in the middle of dissolution vessel.

The concentration of Captopril reaction product was determined by treating it with 2,2dithiodipyridine and absorbance was taken at $344 \mathrm{~nm}$ using ultraviolet spectrophotometer. Dissolution studies were carried out in triplicate to take average. Finally, plots were constructed for drug release (\%) versus time to determine the release profile [19]. The same method was used to determine individual tablet assays after random selection from each batch and crushing them into mortar and pestle. Powdered material equivalent to $50 \mathrm{mg}$ of Captopril was taken to be dissolved in the medium to measure absorbance. 


\section{Data analysis}

The response parameters examined for optimization in the current study were the percentages of drug released at $6 \mathrm{~h}, 12 \mathrm{~h}\left(\mathrm{Q}_{6}\right.$, $\mathrm{Q}_{12}$ ) and the time to liberate $50 \%$ of the drug content $\left(\mathrm{t}_{50 \%}\right)$. Polynomial models comprising quadratic and interaction terms were developed for aforementioned release variables using the multiple linear regression analysis (MLRA). The general MLRA model form is shown in Eq 1.

$$
\mathrm{Y}=\mathbb{F} o+\beta_{1} \mathrm{X}_{1}+\beta_{1} \mathrm{X}_{2}+\beta_{1}^{2} \mathrm{x}_{1} \mathrm{X}_{2}+\beta_{1}^{2} \mathrm{X}_{1}^{2}+\beta_{2}^{2} \mathrm{X}_{2}^{2} \ldots
$$

where $\beta 0$ is the intercept representing the average value of all quantitative results of nine proceeds, $\beta_{1}$ and $\beta_{2}$ are the calculated coefficients from actual values of $Y, Y$ is the response variables $\left(t_{50 \%}, Q_{6}\right.$ and $\left.Q_{12}\right)$ and $X_{1}, X_{2}$ represents the translated levels of the control variables for HPMC K100M and xanthan gum, respectively.

\section{Kinetic modeling of release data}

Drug release profiles from Captopril matrices were analyzed to identify the contribution of different models to the overall kinetics like Higuchi square root kinetics [24], zero-order, First-order and Korsemeyer-Peppas models [25, 26] by using DDSolver.

\section{RESULTS}

\section{Physical evaluation}

Physical characteristics of the prepared tablets were shown in Table 3. In different formulations, the contents of drug determined varied between $96.21 \%$ and $100.43 \%$. Formulation excipients, i.e. xanthan gum, HPMC K100M, PVP K30 and lactose did not show any interference with the results of drug contents. The tablet's hardness varied between 2.79 to $3.67 \mathrm{~kg} / \mathrm{cm}^{2}$, the thickness was found to be between 3.95 and $4.33 \mathrm{~mm}$ and the diameter was between 9.82 $\mathrm{mm}$ and $10.80 \mathrm{~mm}$. Physical parameters of the fabricated matrices were within acceptable range.

\section{Thermal characteristics}

DSC curves of pure Captopril, HPMC K100M, xanthan gum and formulations $\mathrm{F} 4$ and $\mathrm{F} 5$ are shown in Figure 1. An endothermic sharp peak at $108.01{ }^{\circ} \mathrm{C}$ in the spectra of pure Captopril corresponds to the melting point of drug [27]. A broad endothermic peak observed at $112.4{ }^{\circ} \mathrm{C}$ corresponds to the dehydration of HPMC K100M [28] and thermal profile of xanthan gum demonstrated a small endothermic peak at $124.25{ }^{\circ} \mathrm{C}$ which also indicated melting at this temperature followed by exothermic peak at $286.11{ }^{\circ} \mathrm{C}$ which may be due to some polymorphic change in the structure of gum. Similar trend for endothermic DSC curve of xanthan gum was reported by previous study [29]. Sharp endothermic peaks at $108{ }^{\circ} \mathrm{C}$ in the spectra of formulations F4 and F5 correspond to the melting point of drug.

\section{FTIR spectroscopy}

The IR spectra of pure drug, its physical mixture with xanthan gum, HPMC K100M and PVP K30 were recorded to evaluate the compatibility profile (Figure 2). Absorption bands in the spectra of captopril at $2954 \mathrm{~cm}^{-1}$ and $1735 \mathrm{~cm}^{-1}$ correspond to the stretching vibrations of $\mathrm{C}-\mathrm{H}$ bond and carboxyl (COOH-) group, respectively [30]. Spectra of physical mixtures of drug and polymers (xanthan gum, HPMC K100M and PVP K30) showed no remarkable change in the peaks of drug (Figure 2).

\section{In-vitro buoyancy}

Buoyancy characteristics are imparted to floating systems by incorporation of calcium carbonate as a gas generator. The carbon dioxide is produced as a result of reaction of carbonate

Table 3: Physical characteristics of formulated floating tablets (mean $\pm S D, n=3$ )

\begin{tabular}{|c|c|c|c|c|c|c|}
\hline $\begin{array}{l}\text { Formulation } \\
\text { code }\end{array}$ & $\begin{array}{c}\text { Thickness } \\
(\mathrm{mm})\end{array}$ & $\begin{array}{c}\text { Diameter } \\
(\mathrm{mm})\end{array}$ & $\begin{array}{c}\text { Hardness } \\
\left(\mathrm{kg} / \mathrm{cm}^{2}\right)\end{array}$ & $\begin{array}{l}\% \text { Drug } \\
\text { content }\end{array}$ & $\begin{array}{l}\text { Buoyancy } \\
\text { lag time (s) }\end{array}$ & $\begin{array}{c}\text { Floating } \\
\text { duration (h) }\end{array}$ \\
\hline $\mathrm{F} 1$ & $4.09 \pm 0.012$ & $10.17 \pm 0.19$ & $3.16 \pm 0.2$ & 97.27 & $210 \pm 22$ & $8.10 \pm 0.28$ \\
\hline $\mathrm{F} 2$ & $3.97 \pm 0.05$ & $10.05 \pm 0.13$ & $3.24 \pm 0.5$ & 100.13 & $268 \pm 17$ & $12.20 \pm 0.16$ \\
\hline F3 & $3.98 \pm 0.06$ & $10.41 \pm 0.14$ & $3.18 \pm 0.9$ & 99.19 & $235 \pm 15$ & $12.52 \pm 0.35$ \\
\hline $\mathrm{F} 4$ & $4.18 \pm 0.04$ & $10.80 \pm 0.2$ & $3.47 \pm 0.4$ & 98.71 & $246 \pm 10$ & $13.05 \pm 0.06$ \\
\hline F5 & $3.95 \pm 0.01$ & $9.82 \pm 0.12$ & $2.79 \pm 0.2$ & 95.99 & $277 \pm 24$ & $12.58 \pm 0.52$ \\
\hline F6 & $4.32 \pm 0.01$ & $10.60 \pm 0.15$ & $2.95 \pm 0.1$ & 98.21 & $302 \pm 16$ & $12.75 \pm 0.12$ \\
\hline F7 & $4.01 \pm 0.03$ & $10.27 \pm 0.10$ & $3.11 \pm 0.3$ & 96.68 & $260 \pm 13$ & $14.11 \pm 0.77$ \\
\hline F8 & $4.04 \pm 0.02$ & $10.57 \pm 0.17$ & $3.31 \pm 0.6$ & 101.76 & $296 \pm 19$ & $12.18 \pm 0.30$ \\
\hline F9 & $4.03 \pm 0.054$ & $10.43 \pm 0.16$ & $3.67 \pm 0.7$ & 100.84 & $329 \pm 28$ & $13.27 \pm 0.18$ \\
\hline
\end{tabular}




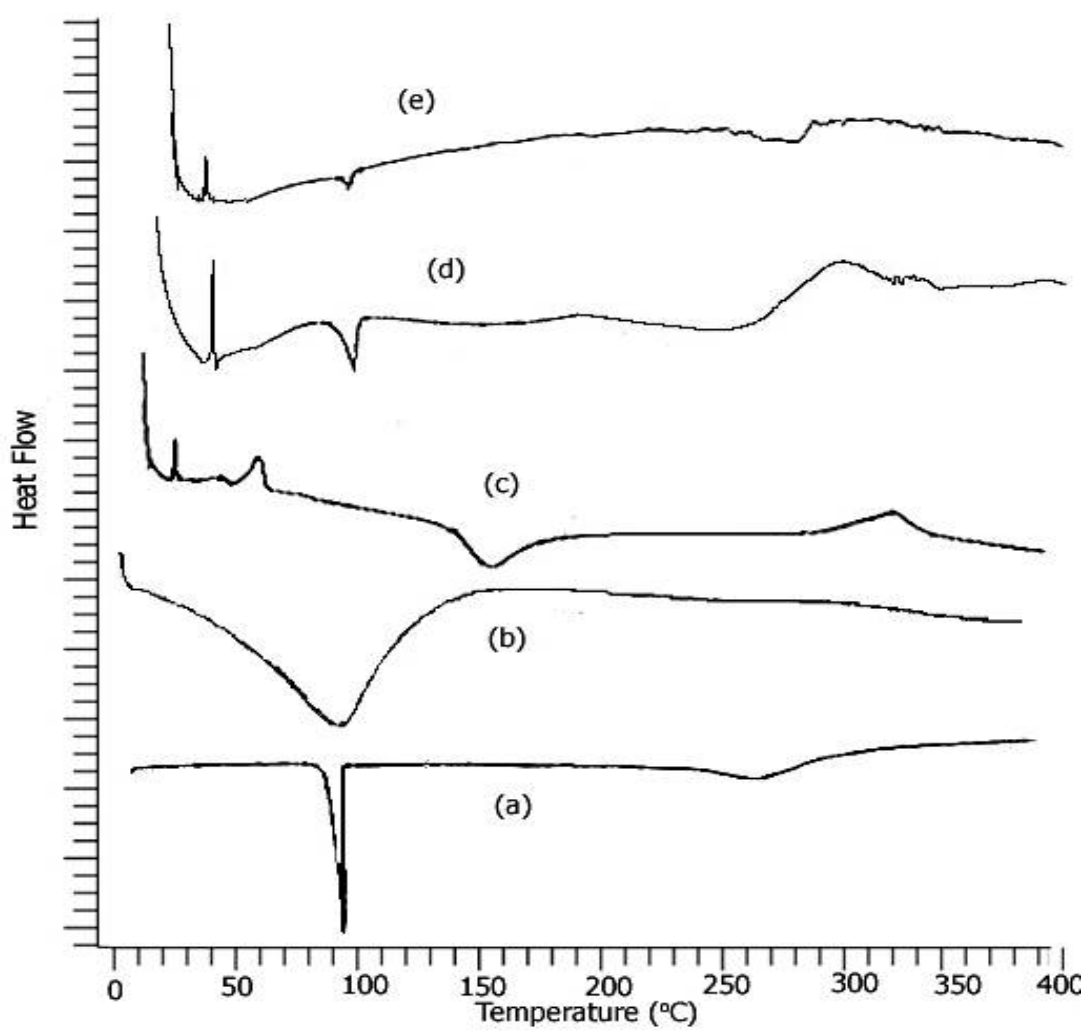

Figure 1: DSC curve of a) Pure Captopril, b) HPMC K100M, c) Xanthan gum, d) Formulation F4 and e) Formulation F5

with dissolution medium $(0.1 \mathrm{~N} \mathrm{HCl})$. In this study, it was noticed that even if the amount of calcium carbonate used was constant $(30 \mathrm{mg}$ ), yet buoyancy lag times possibly changed due to variations in polymer concentrations. However, percentage of carbonate achieved optimum buoyancy lag times between 3.5 to $5.5 \mathrm{~min}$. In addition, captopril tablets floated for the duration of more than $12 \mathrm{~h}$ due to continuous evolution of $\mathrm{CO}_{2}$ from the tablet surface (Table 3).

\section{In-vitro drug release}

Tablets from all the formulations subjected to dissolution tests; the resulting release characteristics as per factorial design are listed in Table 4. The overall results showed that the rate and extent of drug release from floating tablets were controlled by the contents of polymer mix. However, the contribution of HPMC K100M in retarding the drug release was greater as compared with xanthan gum.

Developed formulations exhibited the following desired release pattern i.e $20-25 \%$ in 1-2 h, 25$45 \%$ in $4 \mathrm{~h}, 45-65 \%$ in $6 \mathrm{~h}, 65-75 \%$ in $8 \mathrm{~h}$ and the remaining after $8 \mathrm{~h}$. Formulations F5, F6 and
F9 did not comply with the drug release requirements. Only formulation $\mathrm{F} 4$ was found to be optimum in following the desired prefixed goal for the drug release pattern with floating lag time of $4 \mathrm{~min}$. The remaining formulations also showed acceptable results with minor variations from desirability. Release profile of captopril floating tablets is shown graphically in Figure 3.

\section{Factorial design}

The numerical relationships constructed for the release variables using MLRA approach as in Eqs 2 to 4.

$t_{50 \%}=5.93+0.96 X_{1}+0.81 X_{2}$

$\mathrm{Q}_{6 \%}=45.08-8.78 \mathrm{X}_{1}-7.93 \mathrm{X}_{2}+4.27 \mathrm{X}_{1} \mathrm{X}_{2}+$

$0.387 \mathrm{X}_{1}^{2}+7.436 \mathrm{X}_{2}^{2}$

$\mathrm{Q}_{12 \%}=77.93-7.69 \mathrm{X}_{1}-3.32 \mathrm{X}_{2}+0.88 \mathrm{X}_{1} \mathrm{X}_{2}+$ $2.21 X_{1}^{2}+4.63 X_{2}^{2}$

The application of ANOVA using the provisions of Design expert software revealed statistically significant $(p<0.05)$ values in polynomial terms 


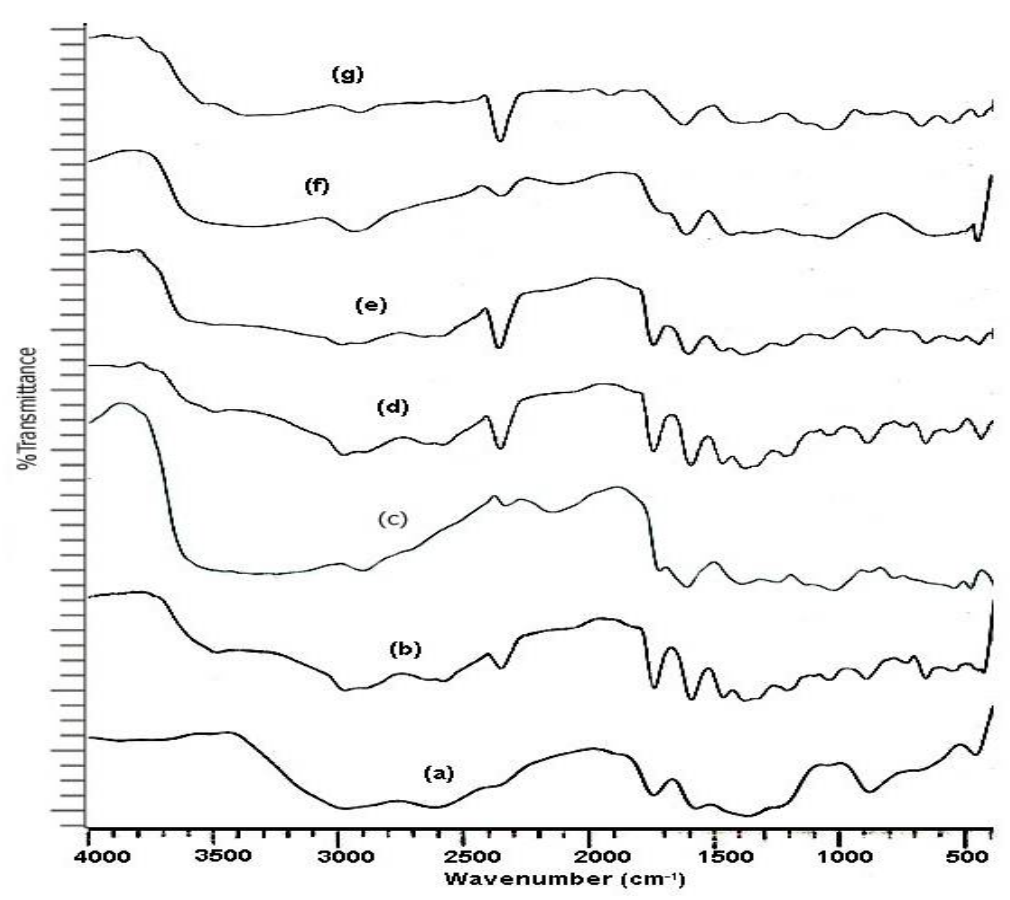

Figure 2: FTIR spectra of (a) pure captopril, (b) captopril + HPMC K100M, (c) captopril + xanthan gum, (d) captopril $+\mathrm{CaCO}_{3}$, (e) captopril + PVP K30, (f) Formulation F4, (g) Formulation F5

Table 4: Dissolution characteristics as per factorial designs (mean $\pm S D n=3$ )

\begin{tabular}{lccccc}
\hline Formulation & $\begin{array}{c}\mathbf{X 1} \\
\text { (HPMC } \\
\text { K100M) }\end{array}$ & $\begin{array}{c}\text { X2 } \\
\text { (Xanthan } \\
\text { gum) }\end{array}$ & $\begin{array}{c}\mathbf{t 5 0 \%} \\
\text { (h) }\end{array}$ & $\begin{array}{c}\text { Q6 } \\
\text { (\%) }\end{array}$ & $\begin{array}{c}\text { Q12 } \\
\text { (\%) }\end{array}$ \\
\hline F1 & -1 & -1 & $3.64 \pm 0.4$ & $73.32 \pm 4.1$ & $96.57 \pm 2.1$ \\
F2 & 0 & -1 & $4.84 \pm 0.9$ & $61.8 \pm 3.2$ & $85.02 \pm 3.9$ \\
F3 & 1 & -1 & $6.38 \pm 0.5$ & $47.01 \pm 2.9$ & $80.46 \pm 2.1$ \\
F4 & -1 & 0 & $4.88 \pm 1.0$ & $54.85 \pm 1.2$ & $92.21 \pm 2.4$ \\
F5 & 0 & 0 & $6.92 \pm 0.4$ & $43.45 \pm 1.1$ & $77.21 \pm 2.4$ \\
F6 & 1 & 0 & $7.02 \pm 0.5$ & $37.72 \pm 2.2$ & $71.79 \pm 1.8$ \\
F7 & -1 & 1 & $6.07 \pm 0.7$ & $49.44 \pm 2.3$ & $86.96 \pm 2.1$ \\
F8 & 0 & 1 & $6.69 \pm 0.12$ & $44.87 \pm 2.5$ & $80.82 \pm 2.2$ \\
F9 & 1 & 1 & $6.97 \pm 0.8$ & $40.22 \pm 3.5$ & $74.37 \pm 2.8$ \\
\hline
\end{tabular}

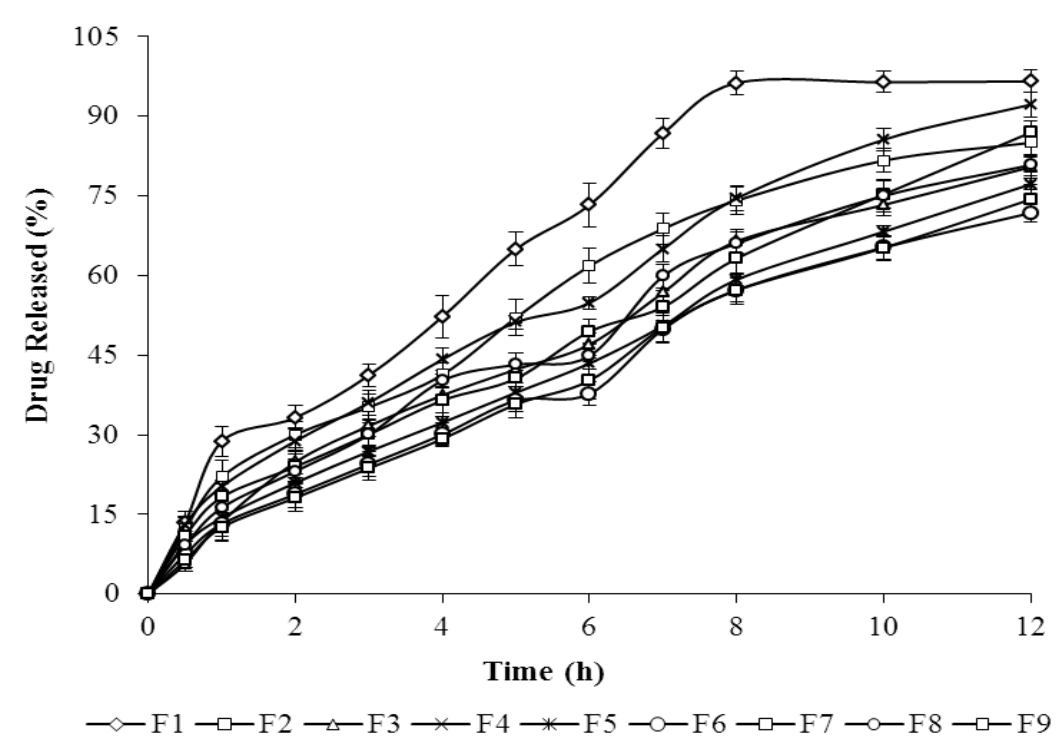

Figure 3: Release profiles of factorial design formulations $(n=6)$ 
These include first order main effects, the higher order effects, coefficients for intercepts, and interaction terms. Furthermore, useful inferences can be drawn by mathematical equations after carefully looking at the values of the main effects which indicate the effect of each control factor on the response.

Figures 4a-6a shows plots of the levels of HPMC $\operatorname{K100M}\left(X_{1}\right)$ and xanthan gum $\left(X_{2}\right)$ versus $t_{50 \%}$, $Q_{6}$, and $Q_{12}$ respectively. Figures $4 b-6 b$ shows the corresponding contour plots for the release variables, i.e., $t_{50 \%}, Q_{6}$, and $Q_{12}$ respectively. These plots were drawn using Stat-Ease Design Expert 9.

\section{Check point analysis}

The validity of the above equations was verified by designing three checkpoint formulations (C1-
C3) and by determining response values for each dependent variable. The response values predicted from the model were compared with those obtained from experimental results. Upon validation by the prediction error, the values of release variables varied between -5.32 and 10.02. The check point analysis terms were shown in Table 5.

\section{Kinetic modeling of drug release}

The correlation coefficient $\left(R^{2}\right)$ was calculated in each case using software program called DDSolver from which mode of release was determined. The kinetic parameters were given in Table 6. Based upon the correlation coefficient, Peppas model showed best fit for the prepared formulations.
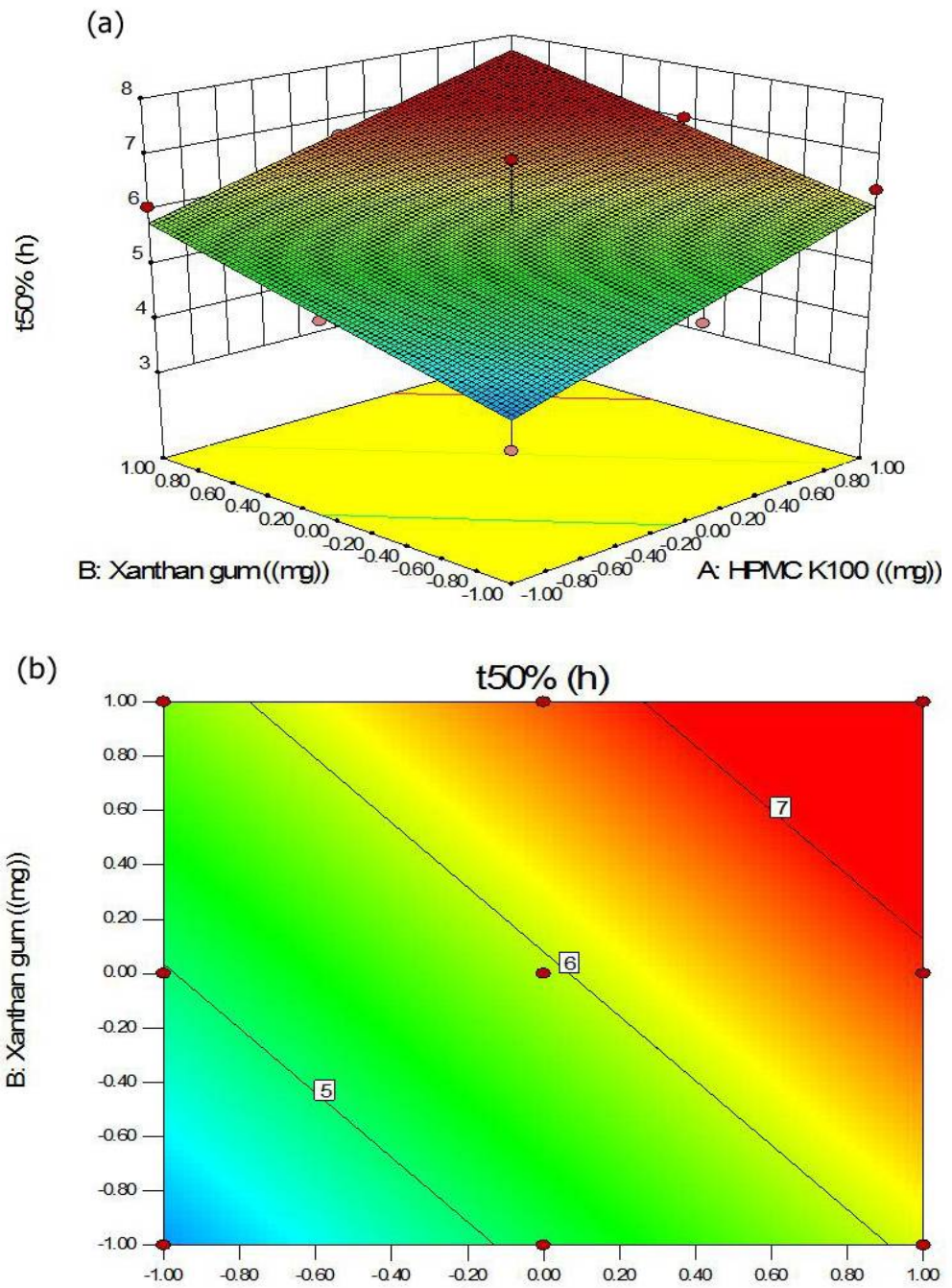

A: HPMC K100 ((mg))

Figure 4: (a) Surface design of response $t 50 \%$ by varying quantities of HPMC K100M and Xanthan gum. (b) Related contour plot indicating various levels of the two polymers 


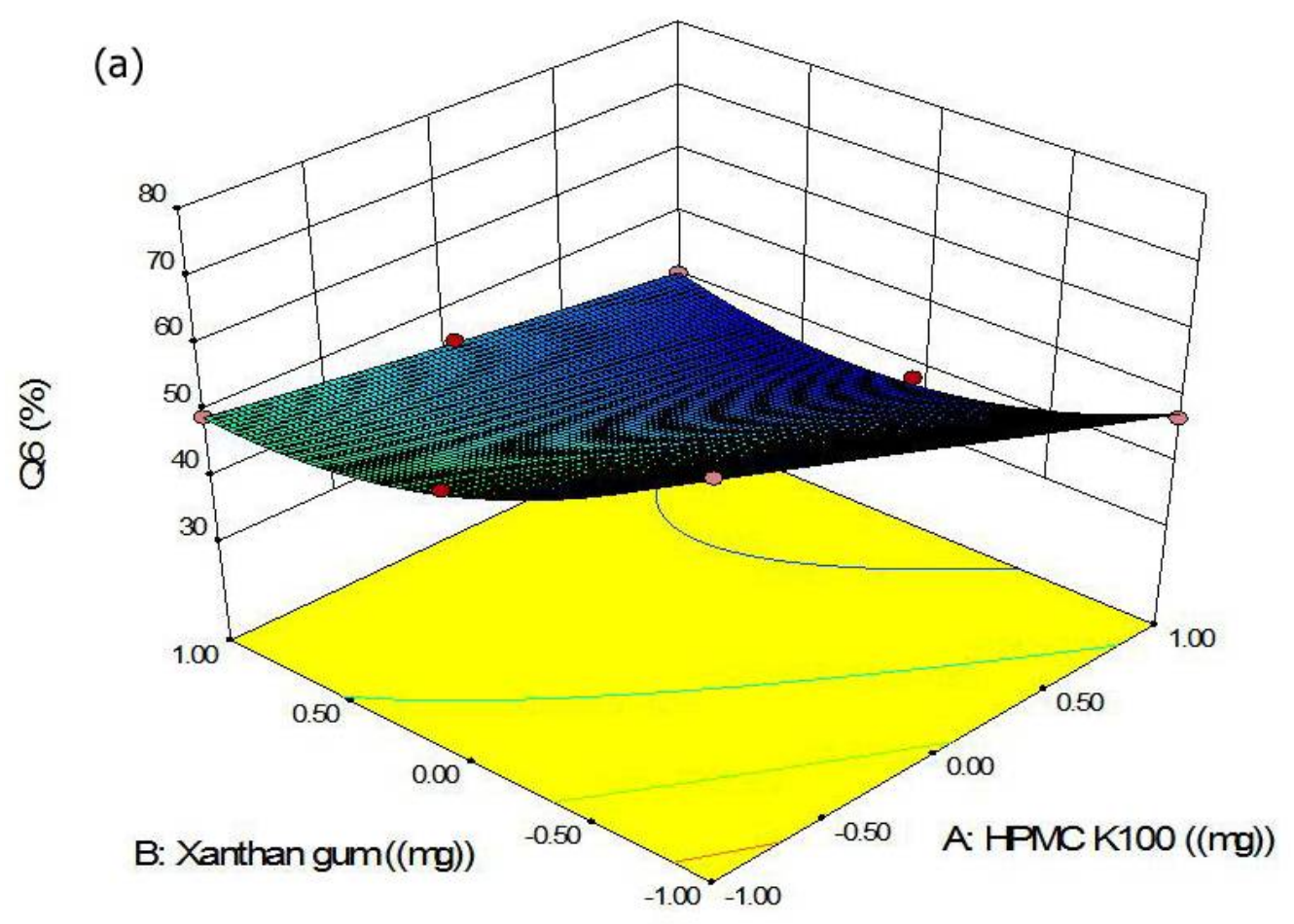

(b)

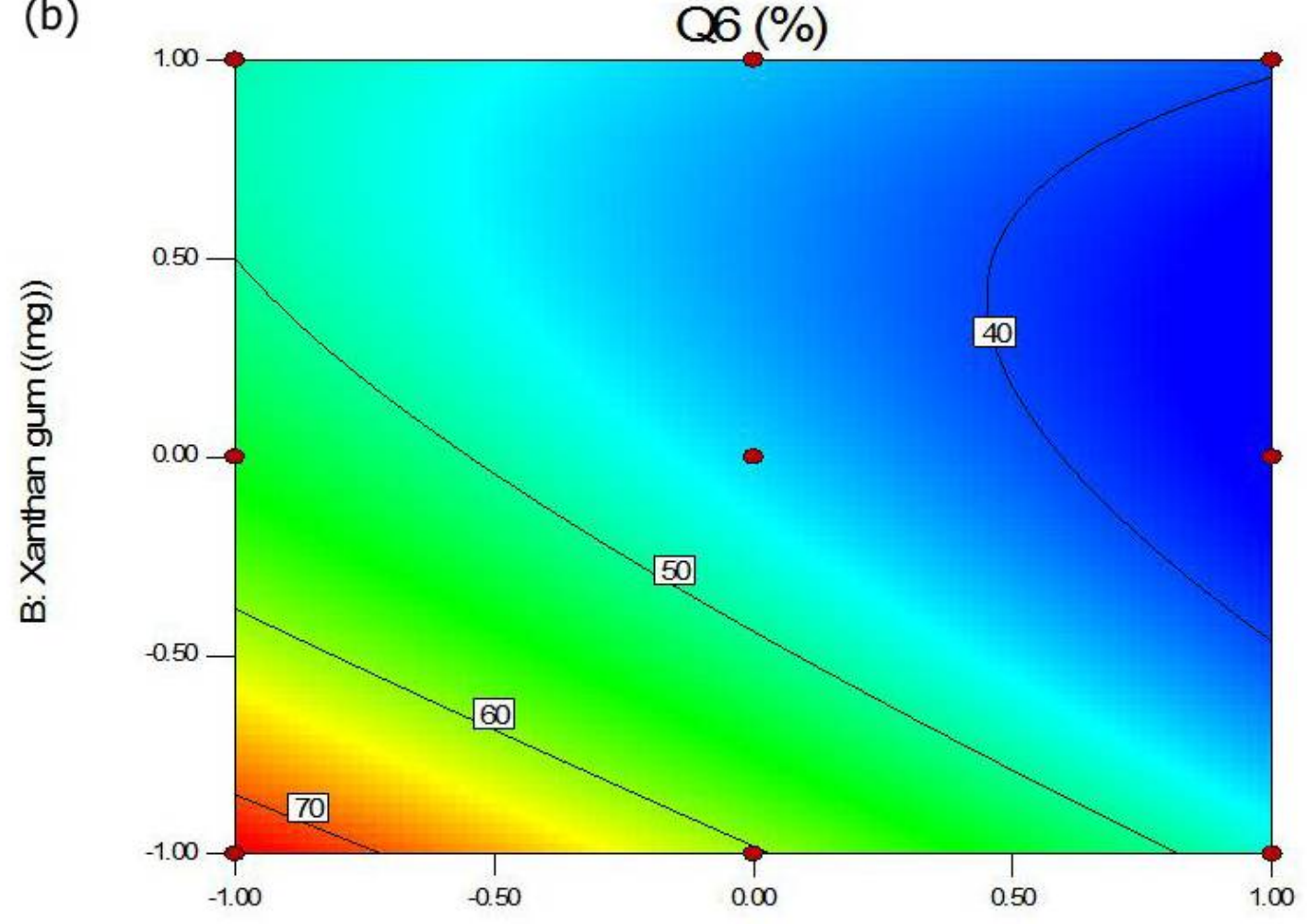

\section{A: HPMC K100 ((mg))}

Figure 5: (a) Surface design of response Q6\% by varying quantities of HPMC K100M and Xanthan gum. (b) Related contour plot indicating various levels of the two polymers 


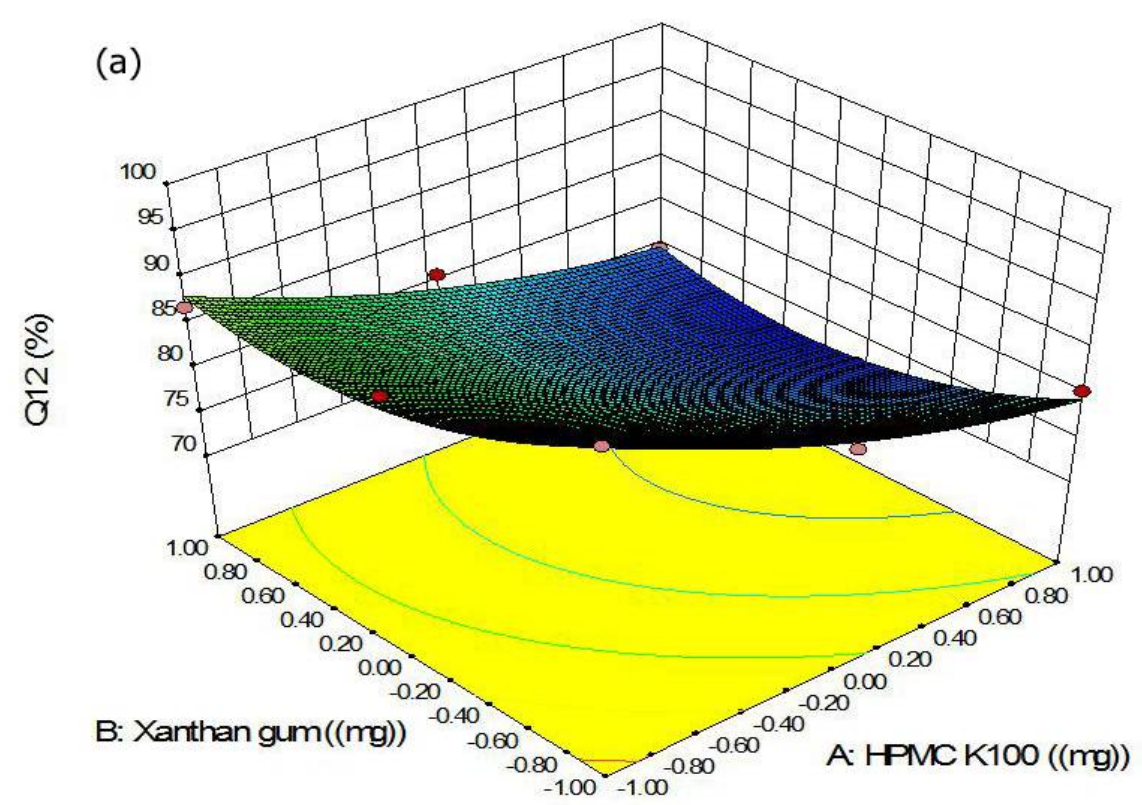

(b)

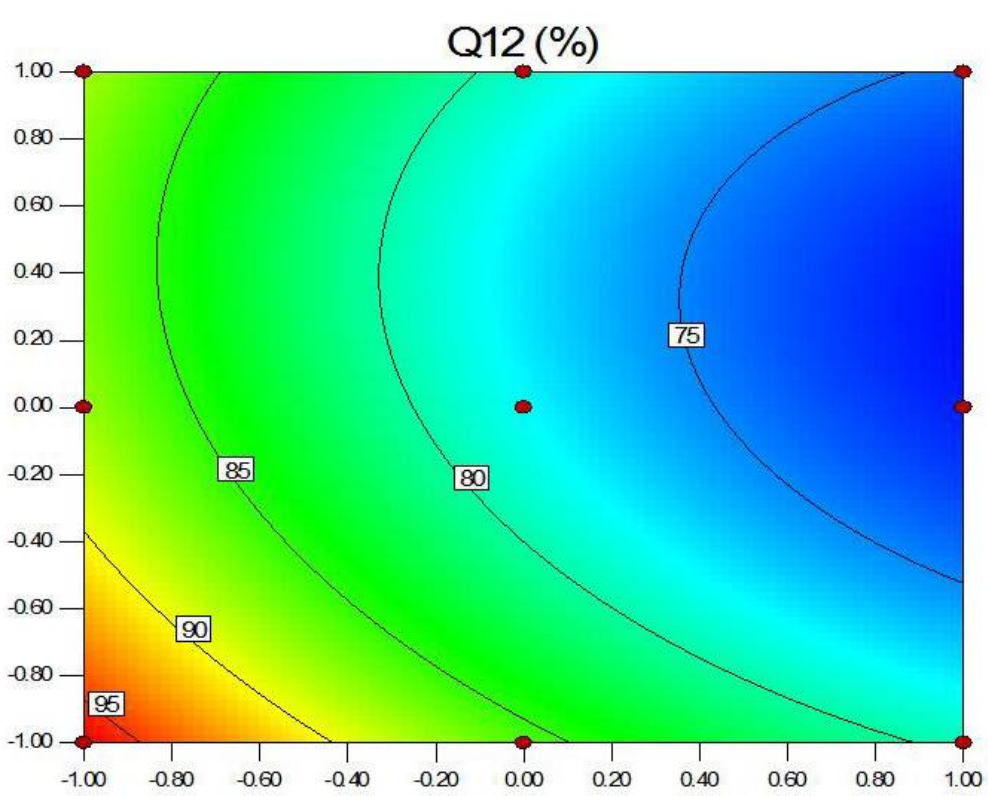

A: HPMCK100 ((mg))

Figure 6: (a) Surface design of response Q12\% by varying quantities of HPMC K100M and Xanthan gum. (b) Related contour plot indicating various levels of the two polymers

Table 5: Analysis of three extra-design checkpoints

\begin{tabular}{|c|c|c|c|c|c|c|}
\hline Formulation & $\begin{array}{c}\mathrm{X1} \\
(\mathrm{mg})\end{array}$ & $\begin{array}{c}\mathrm{X} 2 \\
(\mathrm{mg})\end{array}$ & $\begin{array}{l}\text { Response } \\
\text { variables }\end{array}$ & $\begin{array}{l}\text { Predicted } \\
\text { value }\end{array}$ & $\begin{array}{c}\text { Experimental } \\
\text { value }\end{array}$ & $\begin{array}{c}\text { Prediction } \\
\text { error }\end{array}$ \\
\hline \multirow[t]{3}{*}{$\mathrm{C} 1$} & 105.6 & 125.85 & t50\% (h) & 5.82 & 5.43 & 6.77 \\
\hline & & & Q6 (\%) & 56.74 & 59.76 & -5.32 \\
\hline & & & Q12 (\%) & 94.28 & 90.72 & 3.78 \\
\hline \multirow[t]{3}{*}{$\mathrm{C} 2$} & 58.62 & 114.09 & t50\% (h) & 3.92 & 3.65 & 6.89 \\
\hline & & & Q6 (\%) & 73.21 & 67.23 & 8.17 \\
\hline & & & Q12 (\%) & 97.09 & 95.17 & 1.98 \\
\hline \multirow[t]{3}{*}{ C3 } & 115.14 & 73.92 & t50\% (h) & 6.09 & 5.48 & 10.02 \\
\hline & & & Q6 (\%) & 59.32 & 55.30 & 6.77 \\
\hline & & & Q12 (\%) & 92.34 & 88.08 & 4.61 \\
\hline
\end{tabular}


Table 6: Kinetic analysis of release data

\begin{tabular}{|c|c|c|c|c|c|c|c|c|c|}
\hline \multirow{2}{*}{ Formulation } & \multicolumn{2}{|c|}{ Zero-order } & \multicolumn{2}{|c|}{ First-order } & \multicolumn{2}{|c|}{ Higuchi } & \multicolumn{3}{|c|}{ Korsemeyer-Peppas } \\
\hline & $\mathbf{R}^{2}$ & $\mathrm{~K}_{0}$ & $\mathbf{R}^{2}$ & $\mathrm{~K}_{1}$ & $\mathbf{R}^{2}$ & $\mathbf{K H}$ & $\mathbf{R}^{2}$ & KP & $\mathbf{N}$ \\
\hline $\mathrm{F} 1$ & 0.8201 & 10.485 & 0.9620 & 0.232 & 0.9562 & 29.527 & 0.9662 & 24.943 & 0.588 \\
\hline $\mathrm{F} 2$ & 0.8632 & 8.704 & 0.9834 & 0.160 & 0.9730 & 24.427 & 0.9877 & 19.796 & 0.609 \\
\hline F3 & 0.9408 & 7.658 & 0.9883 & 0.124 & 0.9468 & 21.216 & 0.9928 & 13.903 & 0.717 \\
\hline $\mathrm{F} 4$ & 0.9037 & 8.772 & 0.9784 & 0.158 & 0.9681 & 24.484 & 0.9932 & 18.289 & 0.651 \\
\hline F5 & 0.9590 & 7.044 & 0.9828 & 0.107 & 0.9388 & 19.444 & 0.9952 & 11.867 & 0.753 \\
\hline F6 & 0.9606 & 6.644 & 0.9822 & 0.098 & 0.9265 & 18.298 & 0.9901 & 10.715 & 0.774 \\
\hline F7 & 0.9519 & 7.781 & 0.9677 & 0.125 & 0.9401 & 21.504 & 0.9914 & 13.432 & 0.741 \\
\hline F8 & 0.9314 & 7.742 & 0.9815 & 0.126 & 0.9484 & 21.482 & 0.9894 & 14.461 & 0.704 \\
\hline F9 & 0.9754 & 6.724 & 0.9846 & 0.099 & 0.9179 & 18.448 & 0.9949 & 10.034 & 0.811 \\
\hline
\end{tabular}

\section{DISCUSSION}

The buoyancy results revealed that increase in floating lag times was associated with increasing concentrations of polymers. This is attributed to the higher levels of polymer that need more time to get hydrated with dissolution medium. The generated gas remains confined inside gel like barrier which produces upward motion and as a result tablets remained buoyant [31].

DSC findings suggested that drug structure remained intact with no interference of polymers. However, disappearance of polymer peaks is attributed to their presence in amorphous form. FTIR analysis of formulations F4, F5 showed characteristic peaks of drug preserved with only slight variations which confirms incompatibility between the constituents of the matrices.

Floating matrices that were examined for release profile showed sustained release pattern without disintegration for $12 \mathrm{~h}$. Only formulation F1 suffered disintegration after $8 \mathrm{~h}$ and released almost the entire drug into the dissolution medium. This was because of low levels of HPMC K100M and xanthan gum used in this formulation, strength of gel layer was comparatively poor and hence gas entrapment was not sustained.

Formulations F4 and F7 with lower levels (40 $\mathrm{mg}$ ) of HPMC K100 M and comparatively higher levels of xanthan gum ( 80 and $120 \mathrm{mg}$ ) showed $54.85 \%$ and $49.44 \%$ drug release respectively after $6 \mathrm{~h}$. This rate of drug release was slightly faster than those polymer blends with higher proportion of HPMC K100M. This observation clearly showed that high HPMC contents are responsible for drug retardation which was due to formation of greater quantity of gel [32]. The gas entrapped gel network retards drug release by increasing diffusion path length of the drug; hence, a slowing down of drug release was achieved [32-35]. Moreover, increasing percentage of xanthan gum also contributes towards reduction in release rate of Captopril due to formation of a highly viscous gel structure on the surface of floating tablets. Due to hydration of gum, the swollen particles coalesces which results in viscoelastic layer maintaining integrity of dosage form as well as limiting permeation of dissolution medium. The findings are in agreement with already published reports [22, 36].

Dissolution profiles showed significant variations in factorial design response parameters. Formulated floating tablets released 37.37 to $73.32 \%$ drug at the end of $6 \mathrm{~h}$ and $71.79 \%$ to $96.57 \%$ release occurred at the end of $12 \mathrm{~h}$. The response variables of prepared formulations were recorded in Table 3 . It was evident that strong correlation existed between the values of $t_{50 \%}, Q_{6}$, and $Q_{12}$ and the levels of control variables. This relationship was further justified by the fitted polynomial equations. It can be noticed that the effect of HPMC K100M concentration was the main effect as seen from its higher regression coefficients $(0.96,-8.78$, and -7.69), but the overall trend of drug retardation was controlled by both polymers.

Data after translating into various response surfaces exhibited that $t_{50 \%}$ raised from $3.64 \mathrm{~h}$ to $7.02 \mathrm{~h}$ while $\mathrm{Q}_{6}$ and $\mathrm{Q}_{12}$ decreased with increasing contents of the polymers. Thus, the design of formulation revealed the required levels of control factors (polymers) for controlled delivery of drug with the desired release characteristics. The closeness of the predicted and the actual values, as shown by prediction error, indicated the validity of the derived equations for the response and control variables.

Formulation F4 exhibited value of $R^{2}=0.9932$ for Korsemeyer-Peppas equation indicating zero order release for this matrix system. Furthermore, the values of diffusion exponent (n) studied for nine formulations varied between 
0.588 and 0.811 , indicating non-fickian (diffusion and polymer relaxation) profile of drug release.

\section{CONCLUSION}

The findings of this study indicate that the gel forming polymers, xanthan gum and HPMC $\mathrm{K} 100 \mathrm{M}$, can be effectively blended with a gas generator $\left(\mathrm{CaCO}_{3}\right)$ to achieve an in-vitro captopril floating delivery system. The current methodological study involving $3^{2}$ full-factorial designs showed that the desired dissolution profile depends on selecting suitable compositions of hydrophilic polymers. The tablets of Captopril showed promising results in terms of buoyancy lag times and floating duration. Excellent ability of floating in optimized formulations can possibly increase gastric stay time to ameliorate the problem of low bioavailability.

\section{ACKNOWLEDGEMENT}

The authors are grateful to M/S Wilshire Pharmaceuticals for providing required resources and facilities like FTIR, and dissolution testing etc.

\section{REFERENCES}

1. Zhang C, Xu M, Tao X, Tang J, Liu Z, Zhang $Y$, Lin X, He $H$, Tang $X$. A floating multiparticulate system for ofloxacin based on a multilayer structure: In-vitro and invivo evaluation. Int J Pharm 2012; 430(1): 141-150.

2. Chueh $\mathrm{H}$, Zia H, Rhodes C. Optimization of sotalol floating and bioadhesive extended release tablet formulations. Drug Dev Ind Pharm 1995; 21(15): 17251747.

3. Sungthongjeen $S$, Sriamornsak $P$, Puttipipatkhachorn $S$. Design and evaluation of floating multi-layer coated tablets based on gas formation. Eur J Pharm Biopharm 2008; 69(1): 255-63.

4. Zhao L, Yang $X, X u R, W u$ J, Gu S, Zhang L, Gong P, Chen $H$, Zeng F. Safety, tolerability and pharmacokinetics of phenoprolamine hydrochloride floating sustained-release tablets in healthy Chinese subjects. Int J Pharm 2009; 377(1): 99-104.

5. Deshpande AA, Shah $\mathrm{NH}$, Rhodes CT, Malick W. Development of a novel controlled-release system for gastric retention. Pharm Res. 1997; 14(6): 815-819.

6. Svirskis $D$, Seyfoddin A, Chalabi S, In Kim JH, Langford C, Painter S, Painter A, Al-Kassas R. Development of mucoadhesive floating hollow beads of acyclovir with gastroretentive properties. Pharm Dev Technol 2013; 19(5): 571-576.

7. Santus G, Lazzarini C, Bottoni G, Sandefer EP, Page RC, Doll WJ, Ryo UY, Digenis GA. An in-vitro-in-vivo investigation of oral bioadhesive controlled release furosemide formulations. Eur J Pharm Biopharm 1997; 44(1):39-52.

8. Chawla G, Bansal A. A means to address regional variability in intestinal drug absorption. Pharm tech 2003; 27: 50-68.

9. Dave BS, Amin AF, Patel MM. Gastroretentive drug delivery system of ranitidine hydrochloride: formulation and in-vitro evaluation. AAPS PharmSciTech 2004; 5(2): 77-82.

10. El Gamal SS, Naggar VF, Allam AN. Optimization of acyclovir oral tablets based on gastroretention technology: factorial design analysis and physicochemical characterization studies. Drug Dev Ind Pharm. 2011; 37(7):855-867.

11. Tadros MI. Controlled-release effervescent floating matrix tablets of ciprofloxacin hydrochloride: Development, optimization and $<$ is in-vitro-in-vivo</i> evaluation in healthy human volunteers. Eur J Pharm Biopharm. 2010; 74(2):332-339.

12. Bomma R, Swamy Naidu R, Yamsani M, Veerabrahma $K$. Development and evaluation of gastroretentive norfloxacin floating tablets. Acta pharmaceutica. 2009;59(2):211-221.

13. Gambhire MN, Ambade KW, Kurmi SD, Kadam VJ, Jadhav KR. Development and in-vitro evaluation of an oral floating matrix tablet formulation of diltiazem hydrochloride. AAPS PharmSciTech. 2007; 8(3):E166E74.

14. Seta $Y$, Higuchi F, Kawahara $Y$, Nishimura $K$, Okada $R$. Design and preparation of captopril sustained-release dosage forms and their biopharmaceutical properties. Int J Pharm. 1988; 41(3):245-254.

15. Miyazaki N, Shionoiri H, Uneda S, Yasuda G, Gotoh E, Fujishima S, Kaneko Y, Kawahara $Y$, Yamazaki $Y$. Blood concentration and urinary excretion of captopril (SQ 14,255), angiotensin converting enzyme activity and RAA system after administration of captopril--in patients with chronic renal failure compared with essential hypertension. Nihon Jinzo Gakkai shi 1982; 24(4):421-428.

16. Nur AO, Zhang JS. Recent progress in sustained/controlled oral delivery of captopril: an overview. Int J Pharm 2000; 194(2): 139-146.

17. Cheng $W-T$, Wang $S-L$, Lin $S-Y$. Solid-state interaction study on the captopril/lubricants systems accelerated by grinding process. J Phys Chem Solids 2008; 69(4):1007-1016.

18. Khadka P, Ro J, Kim H, Kim I, Kim JT, Kim H, Cho JM, Yun G, Lee J. Pharmaceutical particle technologies: An approach to improve drug solubility, dissolution and bioavailability. Asian J Pharm Sci 2014; 9: 304-316.

19. Jiménez-Martínez I, Quirino-Barreda T, Villafuerte-Robles L. Sustained delivery of captopril from floating matrix tablets. Int J Pharm. 2008; 362(1):37-43.

20. Sakeer K, Al-Zein H, Hassan I, Martin GP, Nokhodchi A. Use of xanthan and its binary blends with synthetic polymers to design controlled release formulations of

Trop J Pharm Res, October 2015; 14(10): 1747 
buccoadhesive nystatin tablets. Pharm Dev Technol 2010; 15(4): 360-368.

21. Talukdar MM, Michoel A, Rombaut $P$, Kinget $R$. Comparative study on xanthan gum and hydroxypropylmethyl cellulose as matrices for controlled-release drug delivery I. Compaction and invitro drug release behaviour. Int $J$ Pharm. 1996; 129(1):233-241.

22. Hamza YE-S, Aburahma MH. Design and in-vitro evaluation of novel sustained-release double-layer tablets of lornoxicam: utility of cyclodextrin and xanthan gum combination. AAPS PharmSciTech 2009; 10(4): 1357-1367.

23. Sunil SA, Srikanth MV, Rao NS, Balaji S, Murthy KVR. Design and evaluation of lornoxicam bilayered tablets for biphasic release. Braz J Pharm Sci 2012; 48(4): 609619.

24. Higuchi T. Mechanism of sustained-action medication. Theoretical analysis of rate of release of solid drugs dispersed in solid matrices. J Pharm Sci 1963; 52(12): 1145-1149.

25. Korsmeyer RW, Gurny R, Doelker E, Buri P, Peppas NA. Mechanisms of solute release from porous hydrophilic polymers. Int J Pharm 1983; 15(1): 25-35.

26. Peppas N. Analysis of Fickian and non-Fickian drug release from polymers. Pharm Acta Helv 1984; 60(4): 110-111.

27. Macêdo R, Gomes do Nascimento T, Soares Aragăo $C$, Barreto Gomes A. Application of thermal analysis in the characterization of anti-hypertensive drugs. $J$ Therm Anal Calorim 2000; 59(3): 657-661.

28. Vueba M, Batista de Carvalho L, Veiga F, Sousa J, Pina $M$. Influence of cellulose ether mixtures on ibuprofen release: MC25, HPC and HPMC K100M. Pharm Dev Technol 2006; 11(2): 213-228.

29. Ramasamy $T$, Kandhasami UDS, Ruttala H, Shanmugam S. Formulation and evaluation of xanthan gum based aceclofenac tablets for colon targeted drug delivery. Braz J Pharm Sci 2011; 47(2): 299-311.

30. Coates J. Interpretation of infrared spectra, a practical approach. Enc Anal Chem. 2000.

31. Gutiérrez-Sánchez PE, Hernández-León A, VillafuerteRobles L. Effect of calcium carbonate on the properties of metronidazole floating matrix tablets. Drug Dev Ind Pharm 2008; 34(2): 171-180.

32. Chavanpatil MD, Jain $P$, Chaudhari $S$, Shear $R$, Vavia $P R$. Novel sustained release, swellable and bioadhesive gastroretentive drug delivery system for ofloxacin. Int $J$ Pharm 2006; 316(1): 86-92.

33. Singh B, Chakkal SK, Ahuja N. Formulation and optimization of controlled release mucoadhesive tablets of atenolol using response surface methodology. AAPS PharmSciTech 2006;7(1): E19-E28.

34. Singh B, Ahuja N. Development of controlled-release buccoadhesive hydrophilic matrices of diltiazem hydrochloride: optimization of bioadhesion, dissolution, and diffusion parameters. Drug Dev Ind Pharm 2002; 28(4): 431-442.

35. Nafee NA, Ismail FA, Boraie NA, Mortada LM. Mucoadhesive delivery systems. II. Formulation and invitro/in-vivo evaluation of buccal mucoadhesive tablets containing water-soluble drugs. Drug Dev Ind Pharm 2004; 30(9): 995-1004.

36. Yeole $P$, Galgatte $U$, Babla I, Nakhat $P$. Design and evaluation of xanthan gum-based sustained release matrix tablets of diclofenac sodium. Ind $J$ Pharm Sci 2006; 68(2): 185-189. 